\title{
Designing E-content for Teaching Basic Analytical Chemistry in Higher Education: A Baseline Study
}

\author{
Ruby Hanson* \\ Department of Chemistry Education, Faculty of Science Education, University of Education, Winneba, Ghana
}

*Corresponding Author: maameruby@yahoo.com

\section{ABSTRACT}

This study developed an e-resource for six topics and six activities for CHE 242 that could be implemented through the hybrid learning approach. The research employed the analysis, design, development, implementation, and evaluation model but particularly focused on the analysis phase only, in this study. One hundred and two students who enrolled in semester 1 of the 2016/2017 academic year chemistry major class participated in the study. The instrument for data collection was the basic analytical chemistry concept test. The results from the test showed that the participants were weak in answering conversion factor, computational, and stoichiometric problems. They also had challenges with fundamental conceptual problems such as understanding and applying principles about limiting reactants, percentage yield, and chemical reactions. These observed weaknesses were noted to be incorporated into building an e-content that would ensure that students have adequate electronic or online practice to overcome their challenges in learning basic analytical chemical concepts.

KEY WORDS: analysis, design, development, implementation, and evaluation model; analytical chemistry; hybrid learning; information and communication technology

\section{INTRODUCTION}

T eaching is an enterprise that could lead the way to national development, if a nation chooses to educate its populace appropriately. The teaching job has become more challenging now because society expects teachers to equip learners with modern skills of learning - which is basically through integrated technology (Driscoll, 2019; Hanson, 2016; Hanson and Asante, 2014). Information and communication technology (ICT) in teacher education and teaching has become important issues to deal with. It has been found to be effective in establishing social skills, enhancing adult and self-learning, and providing opportunities for sharing information across the globe. In other words, it assists learners to acquire needed skills and knowledge through interchange, interaction, and group work. This implies that teachers have to learn to provide more flexible and innovative fun-filled ways of using ICT to teach for best results (Gyamfi and Gyaase, 2015). This would also enable teacher trainees to learn how to apply ICT in the acquisition of transferrable and lifelong skills. In view of this, the University of Education, Winneba (UEW), Ghana, attempted to give training to its academic staff in the years 2012-2014 with the aim to develop hybrid or blended e-learning courses, especially to support its distant mode programs.

E-content/curriculum is a course material developed in digital form, such as video, simulation, animation, audio, graphic, and many more, that can be assessed online. If a course is designed to be delivered partly in digital form and partly through the conventional or traditional face-to-face mode, then it could be said to be blended or hybrid learning. Lee et al. (2018) defined blended learning as a formal education program, in which a student partly learns through online delivery of instruction with student control over time, place, path, and/or pace, and in part under the supervision of an expert, away from home. A similar definition is given by Staker and Horn (2012).

The adoption of blended learning by UEW was to ensure that students got the opportunity to learn in the comfort of their homes when off campus at any time and to expand its student base, as e-learning has the capacity to offer education to a wider populace. Analysis of the UEWs institutional urge to adopt hybrid or blended learning from 2012 has shown little growth in the development of e-courses since the drive ended in 2014. Statistics shows that with 16 academic faculties and 77 departments, 379 courseware out of a total of 3157 were developed by 2014 that gives $12 \%$ of e-courses out of the total expected to be developed. Since then, only 42 more online courses have been developed, making a total of 421 (13\%) blended courses. Interactions with faculty showed that demands on lecturers to mount courses online were overwhelming and overbearing (Hanson and Asante, 2014). Faculty had a short-sighted vision of the implications and potentials of the technologies and how to apply them. They were unsuccessful at giving adequate in-time and on-time support to students. Thus, students lost interest in the blended approach, just as faculty found them too demanding and overbearing to prepare and use. Faculty admitted that they needed further training in the integration of ICT into their teaching strategies.

In blended learning, a program is developed such that instruction is delivered partly online and partly through a face- 
to-face mode. In the same way, students learn partly through the online delivery mode, where they have absolute personal control and responsibility over their time, place, pace, and socialization. Blended learning is basically the integration of the traditional classroom face-to-face mode learning experiences with the e-mode (Garrison and Kanuka, 2009). It must be noted that in hybrid learning, the non-restriction of time, space, pace, and variety of instructional modes are issues of importance and requirements for success (Hanson, 2016).

E-studies have become popular in recent times to allow adult learners, workers, mothers, and people who are geographically separated from desired places of learning to access education (Gyamfi and Gyaase, 2015). Digital technology has been integrated into other disciplines to enhance not only academic outcomes but also economic, financial, and institutional outcomes (Yang and Yenb, 2016; Matei and Vrabie, 2013).

To obtain positive effects, designs for the development of e-courses must follow workable instructional design guidelines that will enable delivery through a learning management system. The analysis, design, development, implementation, and evaluation (ADDIE) model, as shown in Figure 1, was adopted.

For the model to be implemented successfully, designs must scaffold classroom activities and ensure that they fit the learning styles of all the different students in an explorative manner. Thus, in the analysis phase (1), objectives, needs, interest, and existing students' previous knowledge must be identified, for the various delivery modes and possible learning environments. Timelines for activities should also be considered.

In the design phase (2) of the model, assessment tools that would be required to measure the attainment of objectives and media have to be selected. Prototypes, graphic design, user interphase, and content load are determined at this stage. In the development phase (3), data collected from the analysis and design phases are translated into concrete products so that the content and materials for use are created as aligned programs for delivery of concepts that have to be taught. During the

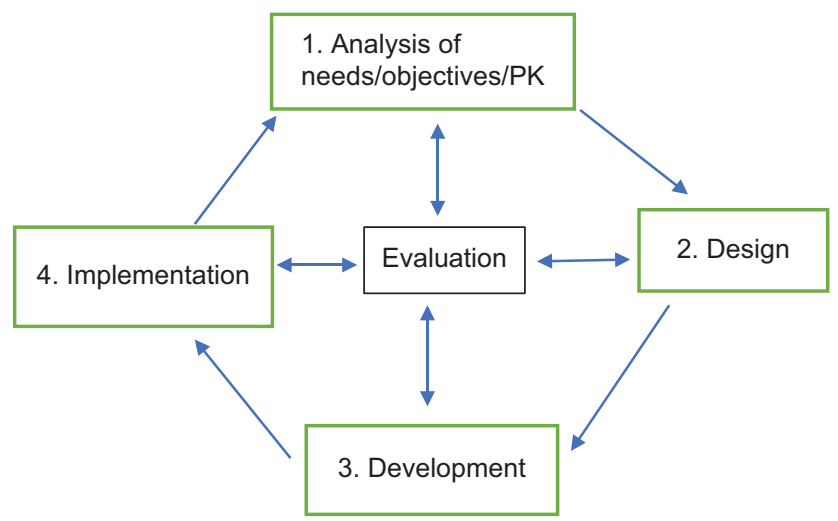

Figure 1: The analysis, design, development, implementation, and evaluation model implementation phase, the program is tested in terms of what, how, why, and if, objectives of the program are successful. This would be an indicator to measure the attainment of goals. This would be very critical in the life of the University of Education as no proper evaluation of its introduction of blended learning in 2014 has been carried out to assess the impact of its intention to roll out e-learning. The ADDIE model has been used in Turkey (Lee et al., 2018). Hitherto, it was used by researchers to develop instructional materials based on the generic ADDIE model (Chen, 2016; Farmer, 2011).

The main objective of this study was to develop innovative, quality, interactive, and engaging learning platforms that were based on national teaching standards (Ministry of Education, 2017) and to strengthen the teaching and learning process so as to produce holistic balanced graduates. It was hoped that these graduates who would be equipped with lifelong learning skills would ensure financial sustainability, innovative ecosystems, demonstrate critical thinking, be globalized online learners, and also transform higher education delivery and the nation, to a higher level. Thus, topics discussed in this course were the relationship among matter, terms of measurement, units of measurement and their relationships, stoichiometry, chemical reactions, statistics, sampling techniques, instrumental analysis, and best practices in analytical work. It was expected that by the end of this course, students would be able to demonstrate laboratory processes and concept skills, apply gained concepts to solve problems, use best methods for inferential analysis of collected analytical data, and design best practices for gathering data with precision and accuracy. They would also be able to demonstrate learning skills such as time management, analytical, deductive, reflective, and noble values such as honesty, tolerance, truthfulness, and love for nature. It was believed that with all these skills that they would acquire from their e-content would cumulatively help them to develop a good scientific and citizenship attitude toward contributing their quota to national development.

Unfortunately, not all chemistry courses can be developed effectively for the hybrid mode delivery with the projected microscale equipment (MSE) for use in economic and resourceconstrained environments. Thus, courses for such an action must be selected carefully for the best results. For example, practical activities that require the use of concentrated tetraoxosulfate (VI) would not be suitable in cases where the plastic MSE is in use. However, if the equipment is made of glass, as some Asian institutions have developed, then they would be suitable for use with concentrated tetraoxosulfate (VI) and high heat.

The course titled Introduction to Analytical Chemistry, with a course code CHE 242, is an important course in the study of chemistry education for chemistry educators and industrial chemistry, for students who wish to pursue industrial careers. CHE 242 is offered to year 2 students in their second semester because it is also a pre-requisite to CHE 243. Fundamental concepts that are required for laboratory analytical work in the $3^{\text {rd }}$ year, and $4^{\text {th }}$ year, as well students' laboratory project works are required for this course. 


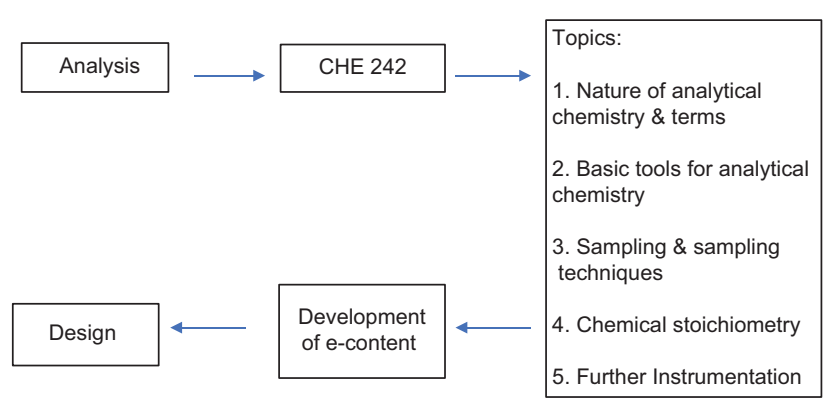

Figure 2: Conceptual framework adapted from Seels and Glasgow (1998)

During the face-to-face mode sessions, microscale chemistry equipment (MSE) activities and macro/conventional activities that do not lend themselves to the use of MSE (as those that require excessive heat and concentrated sulfuric acid) would be carried out in the institutional laboratories. Here, students' development of critical thinking, organizational, negotiation, manipulative, precision, and accuracy skills can be assessed. The activities for which about a quarter of e-learning courseware would be built around would be

i. The nature of analytical chemistry terms/definitions

ii. Instrumentation

iii. Matter and laboratory measurements

iv. Sampling and sampling techniques

v. Chemical stoichiometry.

While the laboratory activities would involve

i. Identification and uses of measuring instruments

ii. Basic tools and measurements activities to teach accuracy and precision

iii. Sampling techniques

iv. Separation methods and further instrumentation

v. Chemical stoichiometry.

The content delivery would be implemented in hybrid or blended mode throughout the semester. To find out students' requirements for such a course, their understanding of concepts in the course was assessed. This paper focused on the required analysis using the main research question.

What are the students' levels of understanding of basic analytical chemistry?

The sub-questions specifically assessed students' understanding of each of the central concepts under study.

The conceptual framework for the study is shown in Figure 2.

\section{METHODOLOGY}

This was a baseline study intended to develop a design to embed e-content into an already existing traditional none-content to generate a blended approach to teaching and learning. This covers the first and second phases in the ADDIE model (Seels and Glasgow, 1998). This model serves as a good guide for analyzing, designing, and developing instructional tools for teaching and learning desired skills and concepts. The survey study was to evaluate students' understanding of some basic analytical chemistry concepts, with the hope that the outcome would be used as a guideline in developing the other phases of e-content as well as develop other topics and disciplines for enhanced flexible and the $21^{\text {st }}$ century learning skills in a digital age.

A total sample of 102 students out of a population of 612 science education students who enrolled on the CHE 242 course participated in the study. The sample which comprised 28 females and 74 males (102 in all) was all chemistry major students aged between 18 and 25 years. Permission was sought from the Dean of Science as well as the Head of the Chemistry Department for students to participate in the study. Students' consents were also sought and institutional ethics for research applied for and approved of. Participants were assured of anonymity and the fact that they could withdraw at any time from the research if they so wished.

The instrument used to gather data was developed by the researcher. It was trialed in a comparable non-major chemistry class with a similar course (ISC 242) and as a result, necessary amendment was made. For example, some analytical terms such as "wet ashing," "assay," "taring," and statistical items that required that students show knowledge of how to determine the deviation from the mean error in given data points within sets were adjusted so that they only worked out mean and median. Furthermore, items that required that students convert $\mathrm{p}$-functions of solutions with certain $\mathrm{pH}$ values to molar concentrations were removed from the trial items. This is because it was discovered that the students did not treat topics that bordered on these during their CHE 122 course in their $1^{\text {st }}$ year. In all, 12 questions on analytical chemistry were administered to assess students' prior knowledge of basic concepts. The validity of the content was checked by subject expert colleagues. Item content validity indices were reported as 1.00 . Reliability (KR-20) of the test was 0.8. Some of the administered items are shown in Table 1.

\section{Procedure}

The paper focuses on the "needs analysis" which is the analysis phase in the ADDIE model. The students' prior knowledge of basic analytical chemistry was obtained at the point of entry or analysis stage (pre-assessment). They were given 1 hour to answer a total of 12 structured questions on measurement, stoichiometry, sampling techniques, and analytical instruments, taking into consideration the terms that would be required in the course. Test papers were collected and marked using a prepared scheme. A total of 24 marks were awarded. A correct conceptual answer was awarded 2 full marks while a partial answer that did not fully explain an idea scientifically or logically was awarded 1 mark. A wrong answer was scored 0 and a "no response" was also scored 0 . The total mark that was obtained by each student reflected their knowledge of expected analytical chemistry concepts required for CHE 242. Their performance also reflected the requirements for the design phase that would enable them 


\begin{tabular}{|c|c|c|c|c|}
\hline No. & Topic & $\begin{array}{l}\text { Distribution } \\
\text { of items }\end{array}$ & Total & Sample questions \\
\hline 1. & Terms and definitions & $1 \mathrm{a}, 1 \mathrm{~b}$ & 2 & $\begin{array}{l}\text { 1a. Explain the terms accuracy and precision } \\
\text { 1b. Distinguish between "accuracy" and "precision" }\end{array}$ \\
\hline 2. & Instrumentation & $2 a, 2 b$ & 2 & $\begin{array}{l}\text { 2a. What instrument would you use to measure the amount of salt shown if Figure } 1 \text { ? } \\
\text { 2b. Between the two instruments shown in Figure 2, which would you recommend for measuring } \\
\text { sample X? Explain your choice further }\end{array}$ \\
\hline 3. & Matter and measurement & $3 a, b, c$ & 3 & $\begin{array}{l}\text { 3a. An invariant measure of the content of matter is.... } \\
\text { 3b. Is the force of gravitational attraction between matter and the earth } \\
\text { 3c. What is the distinguishing factor between mass and weight and why do you say so? }\end{array}$ \\
\hline 4. & Sampling techniques & $4 a, b$ & 2 & $\begin{array}{l}\text { 4a. What procedure would you follow to determine an analyte or sample of interest in something } \\
\text { like an ore of gold or bauxite? } \\
\text { 4b. How would you determine percent error? }\end{array}$ \\
\hline 5. & Stoichiometry & $5 \mathrm{a}, \mathrm{b}, \mathrm{c}$ & 3 & $\begin{array}{l}\text { 5a. What is the quantitative relationship among reacting chemical species? } \\
5 \mathrm{~b} \text {. Describe the relationship among reacting species in the given chemical reaction: } \\
5 \mathrm{c} \text {. How many grams of sodium ions }(22.99 \mathrm{~g} / \mathrm{mol}) \text { are contained in } 25 \mathrm{~g} \text { of } \mathrm{Na}_{2} \mathrm{SO}_{4}(142 \mathrm{~g} / \mathrm{mol}) \text { ? }\end{array}$ \\
\hline
\end{tabular}

\section{Table 2: Analysis of students' responses from the analysis phase}

\begin{tabular}{|c|c|c|c|c|c|}
\hline Item & Question & $\begin{array}{c}\text { Wrong } \\
\text { answer, n (\%) }\end{array}$ & $\begin{array}{c}\text { Partially } \\
\text { correct, n (\%) }\end{array}$ & $\begin{array}{c}\text { Correct answer, } \\
\text { n (\%) }\end{array}$ & $\begin{array}{c}\text { No response, } \\
n(\%)\end{array}$ \\
\hline 1 & $\begin{array}{l}\text { 1a. Explain the terms accuracy and precision } \\
\text { 1b. Distinguish between 'accuracy' and 'precision' }\end{array}$ & $70(68.6)$ & $5(4.9)$ & $20(19.6)$ & $6(5.9)$ \\
\hline 2 & $\begin{array}{l}\text { 2a. What instrument would you use to measure the amount of salt shown if } \\
\text { Figure } 1 \text { ? } \\
\text { 2b. Between the two instruments shown in figure 2, which would you } \\
\text { recommend for measuring sample X? Explain your choice further. }\end{array}$ & 19 (18.6) & $16(15.7)$ & $51(50)$ & $5(4.9)$ \\
\hline 3 & $\begin{array}{l}\text { 3a. An invariant measure of the content of matter is .... } \\
3 \mathrm{~b} . . . . \text { is the force of gravitational attraction between matter and the earth } \\
3 \mathrm{c} \text {. What is the distinguishing factor between mass and weight and why do } \\
\text { you say so? }\end{array}$ & $11(10.8)$ & $13(12.7)$ & $67(65.7)$ & $11(10.8)$ \\
\hline 4 & $\begin{array}{l}\text { 4a. What procedure would you follow to determine an analyte or sample of } \\
\text { interest in something like an ore of gold? } \\
\text { 4b. How will you work out the percent error? }\end{array}$ & $16(15.7)$ & $24(23.5)$ & $47(46.1)$ & $15(14.7)$ \\
\hline 5 & $\begin{array}{l}5 \mathrm{a} \text {. What is the quantitative relationship among reacting chemical species? } \\
5 \mathrm{~b} \text {. Describe the relationship among reacting species in the given chemical } \\
\text { reaction: } \\
5 \mathrm{c} \text {. How many grams of sodium ions }(22.99 \mathrm{~g} / \mathrm{mol}) \text { are contained in } 25 \mathrm{~g} \text { of } \\
\mathrm{Na} 2 \mathrm{SO} 4(142 \mathrm{~g} / \mathrm{mol}) \text { ? }\end{array}$ & $36(35.3)$ & $18(17.7)$ & 29 (28.4) & 19 (18.6) \\
\hline
\end{tabular}

to overcome the identified problems and other associated weaknesses from the analysis phase.

\section{RESULTS AND DISCUSSION}

Data obtained from students' answers to the items provided are presented in Table 2 .

Interesting patterns were observed among the students' responses. There appeared to be poor understanding or interpretation of simple English worded problems. They were unable to express their own ideas articulately on paper. The percentage of wrong answers was quite high for item 1, where analytical terms had to be defined. Their inadequate conceptual understanding of basic analytical procedures became evident in their responses to item 4 . The majority of the students gave partial responses about sampling and sampling techniques. There were obvious weaknesses in their ability to use appropriate scientific language.

They also showed difficulties with their computational skills, possibly because their concept of amount of substance was insufficient. It was also obvious from item 5 that the students had poor knowledge of stoichiometry. Equations were not balanced properly as a result of wrong presentation of equations, and these students' inabilities led to many wrong, partial, and no response to item 5 . They could not relate among the various units for expressing matter. Units were converted poorly. Mole ratios were also not observed nor applied appropriately.

\section{The Way Forward}

To overcome this, examples on conversion factors should be provided in designing the e-content. Salient ideas and 
terms that must appear in descriptions of phenomena could be emphasized in the form of videos, cartoons, role play, or other demonstrable distinctive activities. Some of the simple e-activities that students could engage in for practice could be label glassware, use concept mapping to outline sampling procedures, match analytes with best sampling procedures, and do conversion of unit exercises.

A few of the students exhibited their readiness for the course by their high performance on the pre-assessment test. Some of the things that they could do are shown in Figure 3.

From research, students are sometimes able to exhibit prowess with skills that are not deeply ingrained (Hanson and SakyiHagan, 2019; Talanquer, 2017). Such weaknesses can only be exposed when their reasoning patterns are uncovered. To uncover such often unapparent reasoning patterns, provisions must be made for students not only to supply factual answers but also to provide conditions that will enable them to express their deep thoughts or how the pathway by which their answers are derived. Using moving screen visuals (animation or videos), jigsaw puzzles, cartoons, and models have been known to excite learners into communication and sharing ideas so that they arrive at building their own authentic science concepts (Toman and Ergen, 2014; Willimson, 2011). These observations suggest that engaging learners in activities that make them not only observe scenes that will enable them to remember but also to question what they see or do could be an acceptable way to learn and retain what one observes and assimilates. In this way, concepts videos, simulation, and activities that explain and enable learners to understand and apply analytical chemistry terms will have to be integrated onto the e-platform. Besides the analytical terms, the students' comprehension about chemical stoichiometry was also found to be weak and therefore needed to be integrated into the e-course as well. Although students' conceptual understanding about measurement, instrumentation, and sampling was found to be appreciably high, integrating lessons on them onto the e-platform would further enhance their understanding and performance in that course, as a few misconceptions were observed in the answers provided in the pre-assessment test (sample shown in Appendix A).

Some of the identified student misconceptions from this current study that would require remediation in the e-content that is to be developed are shown in Figure 4.

From Figure 4, it is observed that students had challenges with differentiating among analytical terms such as "sample" and "analyte" and overused the term "substance." Regular use of such terms, through practice, will bring out the meaning of the terms better and students will apply them more appropriately.

\section{RECOMMENDATIONS}

An analysis of findings of students' misconceptions from Figure 4 shows that when e-content is to be designed for the introductory part of the analytical chemistry course, activities that will expose students to adequate practice and

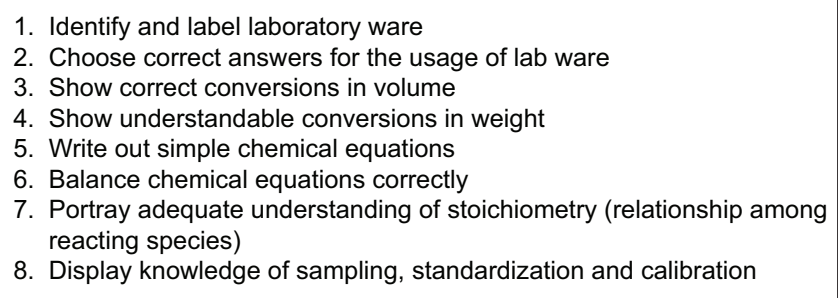

Figure 3: Some examples of the identified students' conceptual strengths

1. Interchanging the terms precision and accuracy

2. Distinction between the terms sample and analyte

3. Interpretation of percentage error, actual yield, and theoretical yield

4. Mistaking descriptions of central tendencies

5. Confusion over mole ratio and its application

6. Misinterpretation and overuse of the term 'substance'

7. Inability to transfer and relate different units of measures of matter

8. Identifying the limiting reactant in a given chemical reaction

9. Mix up about stoichiometric coefficients and subscripts

Figure 4: Some misconceptions that were identified for redress

use of terms, such as precision, accuracy, analyte, titrant, sample, limiting reactant, and many more basic terms akin to those indicated, should be emphasized. As indicated earlier, pictures, videos on titration, virtual activities on titration, and threaded conversations about observations made could go a long way to strengthen students' visualization capacities even further on desired concepts (Williamson, 2011; Garrison and Kanuka, 2009). Before the lesson even rolls out, students must be trained to learn how to use ICT in a preparatory topic as the use of ICT is acceptable to teaching in the $21^{\text {st }}$ century (Driscoll, 2019). Students must be taught about word processing, how to use Excel, make a PowerPoint, connect to the internet, chat synchronously and asynchronously, and other basic computer skills that will facilitate engagement with the e-platform (Jung, 2005). In the absence of the aforesaid, the application of the blended lessons will not be effective. Students will grapple half the time with figuring out what to do with their computers or laptops instead of engaging with the lesson for the day. The ability to employ ICT in teaching and learning activities in UEW will go a long way to facilitate the implementation of the blended learning approach not only in the study of chemistry but also in all other courses.

\section{CONCLUSION}

The ADDIE model was employed in assessing students' level of understanding of basic analytical chemistry. From findings, students were found to have challenges with needed analytical chemistry terms such as limiting reactants, percentage yield, error, and a few more as well as computational skills, especially in chemical stoichiometry. Suggestions for factoring needed requirements into the design of e-content for the hybrid online activities were pooled together for implementation. It is hoped that the teacher trainees will also be able to integrate ICT into their own teaching as teachers because they have experienced it in blended learning (Collins and Jung, 2003). 


\section{Limitations to Existing Program and the Way Forward}

The existing online courseware on UEWs Moodle does not spell out how long it will run before their quality, usefulness, and impact are reviewed. It is imperative that any important program such as the use of blended learning be critically assessed for effectiveness, strengths, and weaknesses after implementation. Thus, this new interactive blended model which is being proposed for the design of e-content courses will have a period of use as well as its impact on teaching and learning assessed for further improvement.

To feel the impact of institutionalization of blended learning, it is proposed that a 10-year adoption and design period for e-courses be carried out in four phases in UEW and other institutions, if possible. In Phase 1, all departments could ensure that $10 \%$ of their courses are in blended or hybrid mode. In Phases 2 and 3, 25\% and 50\% more of departmental courses should be online. Then, in the $4^{\text {th }}$ and last phase, the remaining $50 \%$ of courses will be developed; by which time, most faculty would have gained the expertise in building blended courses, bearing in mind that the courseware must meet international standards.

\section{ACKNOWLEDGMENT}

All prospective teachers who participated in this study are being acknowledged for their willingness to contribute toward the practice of teaching and learning in innovative and interactive ways in higher education.

\section{REFERENCES}

Chen, L.L. (2016). A model for effective online instructional design. Literacy Information and Computer Education Journal, 6(2), 2302-2308.

Collins, B., \& Jung, I.S. (2003). Uses of information and communication technologies in teacher education. In: Robinson, B., \& Latchem, C. (Eds.), Teacher Education through Open and Distance Learning. London: RoutledgeFalmer. p171-192.

Driscoll, M. (2019). The Value of the 21 ${ }^{\text {st }}$ Century Education. Available from: https://www.thinkingstrategicforschools.com. [Last accessed on 2019 Nov 18].

Farmer, L.S. (2011). Instructional Design for Librarians and Information Professionals. $1^{\text {st }}$ ed. New York: Neal-Schuman Publishers Inc.
Garrison, D.R., \& Kanuka, H. (2009). Blended learning: Uncovering its transformative potential in higher education. Internet and Higher Education, 7, 95-105.

Gyamfi, S.A., Gyaase, P.O. (2015). Students' perception of blended learning environment: A case study of the University of Education, Kumasi Campus, Ghana. International Journal of Education and Development using Information and Communication Technology, 11(1), 80-100.

Hanson, R. (2016). Ghanaian teacher trainees' conceptual understanding of stoichiometry. Journal of Education and e-learning Research, 3(1), 1-8.

Hanson, R., \& Asante, J.N. (2014). An exploration of experiences in using the hybrid MOODLE approach in the delivery and learning situations at the University of Education, Winneba, Ghana. Journal of Education and Practice, 5(12), 18-23.

Hanson, R., \& Sakyi-Hagan, N. (2019). Understanding teacher trainees' reasoning patterns about the formation and description of chemical compounds. Science Education International, 30(2), 105-115.

Jung, I. (2005). ICT-Pedagogy integration in teacher-training: Application cases worldwide. Educational Technology and Scociety, 8(2), 94-101.

Lee, T.T., Sharif, A.M., \& Rahim, N.A. (2018). Designing E-content for teaching basic chemistry concepts in higher education: A needs analysis. Journal of Turkish Science Education, 15(4), 65-78.

Matei, A., \& Vrabie, C. (2013). E-learning platforms supporting the educational effectiveness of distance learning programme: A comparative study in administrative science. Procedis-social and Behavioural Sciences, 93, 526-530.

Ministry of Education. (2017). National Teachers' Standard for Ghana: Guidelines. Accra: Ministry of Education. Available from: http:// www.t-tel.org/files/docs/learning\%20hub/teacher\%20 ducation $\% 20$ policies $\% 20$ and $\% 20$ protocols $/$ nts $\% 20$ for $\% 20$ ghana.pdf. [Last accessed on 2020 Jan 17].

Seels, B., \& Glasgow, Z. (1998). Making Instructional Design Decisions. Upper Saddle River, NJ: Merrill Publishing Company.

Staker, H., \& Horn, M.B. (2012). Classifying K-12 Blended Learning. Mountain View, CA: Innosight Institute.

Talanquer, V. (2017). Progressions in reasoning about structure-property relationships. Chemistry Education Research and Practice, 18(4), 559-571.

Toman, O.G., \& Ergen, Y. (2014). Determination of misconceptions belonging to the solar system and beyond: Space puzzle unit in the $7^{\text {th }}$ grade science and technology curriculum with two-tier diagnostic tests. International Journal of Trends in Arts, Sports and Science Education, 3(3), 58-64.

Willimson, V.M. (2011). Teaching chemistry with visualisations: What's the research evidence? In: Diane, M.B. (Ed.), Investigating Classroom Myths through Research on Teaching, ACS Symposium Series 1074. Washington, DC: American Chemical Society. p65-81.

Yang, J.Y., \& Yenb, Y.C. (2016). College students' perspectives of E-learning system use in high education. Asian Journal of Education and Training, $2(2), 53-62$. 


\section{APPENDIX}

\section{Appendix A: Sample Questions From Assessments}

1. How would you call the process of determining the proportionality constant "k" in analysis? Why would you call it as you have chosen to? (Calibration)

2. The quantitative relationship among reacting chemical species is termed (stoichiometry)

3. How many grams of sodium ions $(22.99 \mathrm{~g} / \mathrm{mol})$ are contained in $25 \mathrm{~g} \mathrm{of}_{2} \mathrm{SO}_{4}(142 \mathrm{~g} / \mathrm{mol})$ ? Answer $=8.0 \mathrm{~g} \mathrm{Na}^{+}$

4. An invariant measure of content of matter is (mass)

5. (Weight) is the force of gravitational attraction between matter and the earth.

6. An (outlier) is an occasional result in replicate measurement that differs significantly from the rest of some given results.

7. What does the expression "actual yield" mean?

8. What does the term "percent by mass" (mass percent) mean?

9. What is the percent by mass concentration of $\mathrm{K}_{3} \mathrm{PO}_{4}$ in a solution made by dissolving $134 \mathrm{~g}$ of $\mathrm{K}_{3} \mathrm{PO}_{4}$ in enough water to give $554 \mathrm{~g}$ of solution?

10. In the treatment of diarrhea, a $0.92 \%(\mathrm{~m} / \mathrm{v})$ sodium chloride solution is administered intravenously. How many grams of sodium chloride would be required to prepare $345 \mathrm{ml}$ of this solution?

11. A sample of water on analysis was found to contain $6.3 \times 10^{-3} \mathrm{~g}$ of propoxur per $375 \mathrm{ml}$ of solution. What is the propoxur concentration in:

a) $\mathrm{ppm} \mathrm{m} / \mathrm{v}$, b) $\mathrm{ppb}(\mathrm{m} / \mathrm{v})$ ?

12. How many grams of silver $\left(\mathrm{AgNO}_{3}\right)$ are present in $375 \mathrm{ml}$ of a $1.50 \mathrm{M}$ silver nitrate solution? 